\title{
Advances of Industry 4.0 Concepts on Aircraft Construction: An Overview of Trends
}

\author{
Gustavo Franco Barbosa* and Rafael Vidal Aroca
}

Department of Mechanical Engineering, Federal University of Sao Carlos, Washington Luis Road, São Carlos, Zip code 13565-905, Brazil

\begin{abstract}
This paper reviews the applications of Industry 4.0 concepts within the aerospace manufacturing processes. A contextual overview of Robotics, Additive Manufacturing, Augmented Reality, Internet of Things, Simulation and Aircraft Industry is provided. Some applications of Robotics integrated with other Industry 4.0 principles are showed to present the trends of Industry 4.0 principles in different areas of aircraft manufacturing. This paper presents some innovations in aerospace industry related to Industry 4.0 and how its benefits and advantages can be reached dayby-day. Finally, it has been concluded that Industry 4.0 brings gains productivity, quality, costs reduction and increase the competitiveness of any business.
\end{abstract}

\section{Keywords: Industry 4.0; Aircraft; Manufacturing}

\section{Introduction}

The aircraft manufacturing is an essential segment of the industry. This sector is expected to experience growth, guided by the rising volume of aircrafts be produced for, after to the next decades.

Aviation industry is characterized by demand and its dynamic and competitive environment. The key to successfully compete in this rival scenario is to continuously strive towards higher levels of productivity, which is particularly essential for companies producing in high-wage countries [1].

Aviation industry has quickly improved in terms of technological development and its related manufacturing processes. Thus, it has sought better solutions during the development phase concerning manufacturing processes. The challenge is to find a better-quality final product, minimization of cycle times, manpower labour, and production wastes to aid the company's competitiveness in the global market [2].

Thus, aircraft market requires aircraft manufacturers to drive innovation and development innovative manufacturing processes in order to get competitive.

Faced to these trends, the Industry 4.0 concepts have been looked for improving the whole process in order to increase the productivity of companies. Briefly, in essence, Industry 4.0 is able to offer productivity gains based on collective term for technologies and concepts of value chain organization [3].

Within the Industry 4.0 context, Robotics, Digital Manufacturing, Augmented Reality, Radio Frequency Identification (RFID), Additive Manufacturing (AM), Manufacturing Execution System (MES), Composite Materials and Internet of Things (IoT) are some components of fundamental concepts of that.

On this way, the contribution of this paper is to present an overview of Industry 4.0 concepts inside the aviation fabrication processes and its potential gains, benefits and advantages.

\section{Literature Review}

\section{Aviation industry}

Aircraft manufacturing is one of the most important branch of manufacturing of durable goods due to its high added-value. Also, this sector contributes to the development of new technologies that requires high-skilled professionals [4].

According to [5], aircraft industry looks for potential suppliers of technologies, but these investments should be made with extreme care. This issue is relevant due to the development cost of new products is extremely high in this kind of business. So, errors must be avoided when investments are done in aircrafts fabrication.

Although the number of new transport aircraft has increased over the past decade, production and deliveries have trended steadily. As seen in Figure 1 below, this trend will continue in the coming decade [6].

As presented in the Figure 1, aircraft manufacturers are expected to deliver more than 16,000 aircrafts from 2012 to 2021.

In order to attend the increase of production demands, aircraft manufacturers are looking for improving their processes in order to increase the productivity. Thus, Industry 4.0 concepts have been input in aviation manufacturing environment to innovate and make the business more competitive.

\section{Industry 4.0}

According to [7], industry is the part of an economy that produces goods which are highly mechanized and automatized. Since the beginning of industrialization, technological steps have changed the paradigm which today is named "industrial revolutions" as explained below:

*Corresponding author: Gustavo Franco Barbosa, Department of Mechanical Engineering, Federal University of Sao Carlos, Washington Luis Road, Km 235, São Carlos, Zip code 13565-905, Brazil, Tel: + 5516 99761-3151; E-mail: gustavofb@ufscar.br

Received February 20, 2017; Accepted February 21, 2017; Published February 25, 2017

Citation: Barbosa GF, Aroca RV (2017) Advances of Industry 4.0 Concepts on Aircraft Construction: An Overview of Trends. J Steel Struct Constr 3: 125. doi: 10.4172/2472-0437.1000125

Copyright: (C) 2017 Barbosa GF, et al. This is an open-access article distributed under the terms of the Creative Commons Attribution License, which permits unrestricted use, distribution, and reproduction in any medium, provided the original author and source are credited. 
- $\quad$ 1st: focus on mechanization;

- 2nd: intensive use of electrical energy;

- 3rd: widespread digitalization.

Based on the increase and advance of digitalization within the factories, the conjunction of internet and oriented technologies in the area of "smart" machines and sensors, another new and essential industrial revolution named Industry 4.0 has been born. The focus of future production contains modular and intelligent manufacturing systems and characterizes scenarios in which the products manage their own manufacturing process [7].

The Figure 2 shows the industrial evolution along the years and the 4th industrial revolution [8].

Toward to future expectation, the term "Industry 4.0" was established as the "4th industrial revolution.

Industry 4.0 links the real-life factory with virtual reality and it will play an increasingly important role in global manufacturing [42].

The main concept of Industry 4.0 is to connect by IT systems, sensors, machines and parts along the value chain. These connected systems can interact with one another using standard internet protocols and analyse data to predict failure, configure themselves, and adapt to changes. It will provide conditions to connect and analyse data across machines, enabling faster, more flexible, and more efficient processes to produce higher-quality products at reduced costs. This helps the increase of manufacturing productivity, reduction of wastes, growth in innovation and changes in the people's profile, contributing to the competitiveness of companies and areas [15].

Figure 3 illustrates the Industry 4.0, representing the integration of Cyber and Physical systems concept. It has become a hot topic since its first introduction in 2011 [16].

This figure above shows the nine technology trends that are the building blocks of Industry 4.0 and explores their potential technical and economic benefits for manufacturers and production equipment suppliers.

Thus, this paper has been focused on technologies that have been researched and applied on manufacturing of aviation industry.

\section{Robotics}

There will be an increase of robot's installation around the world. According to [12], between 2015-2018, it is estimated a supply of new industrial robots that will represent 1.3 million dollars (Figure 4).

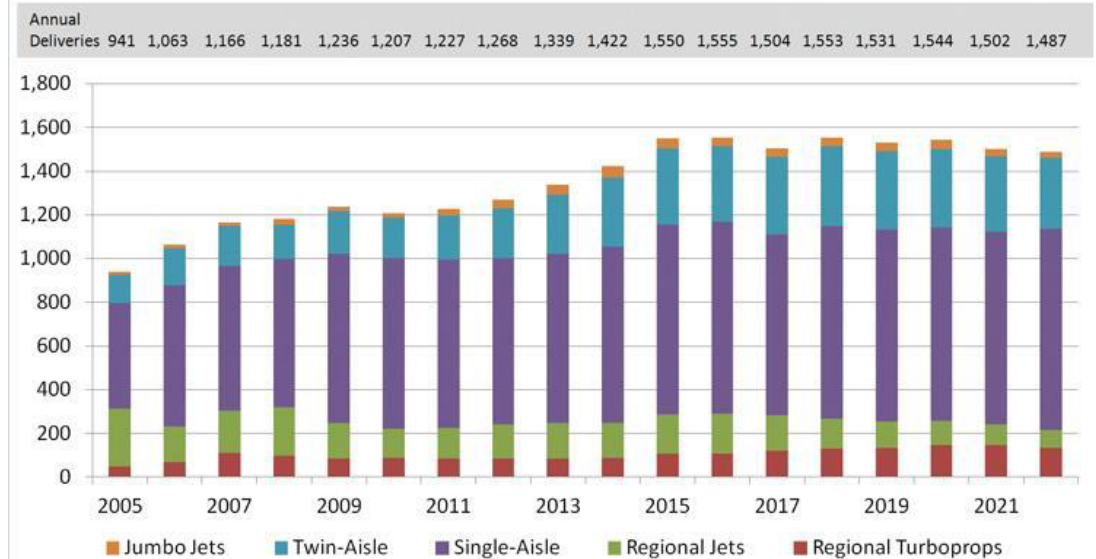

Figure 1: Historic and forecasted commercial aircraft unit deliveries (Composites Forecasts and Consulting LLC) [6].

The 4th Industrial Revolution - „Industry 4.0"

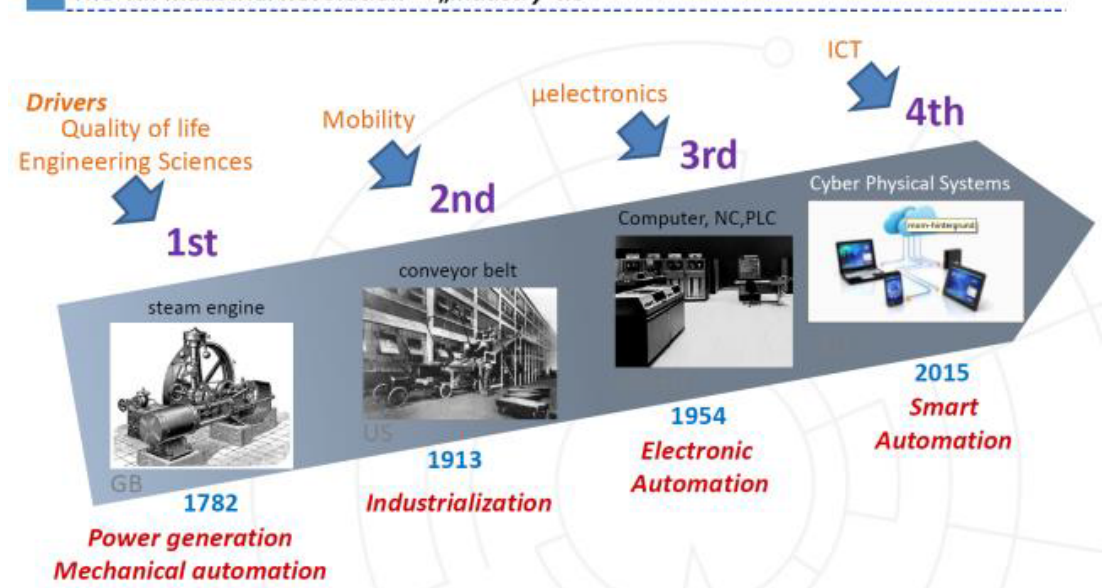

Figure 2: The 4th Industrial Revolution - Industry 4.0 (Lins 2015) [8]. 
Citation: Barbosa GF, Aroca RV (2017) Advances of Industry 4.0 Concepts on Aircraft Construction: An Overview of Trends. J Steel Struct Constr 3: 125 . doi: $10.4172 / 2472-0437.1000125$

Page 3 of 8

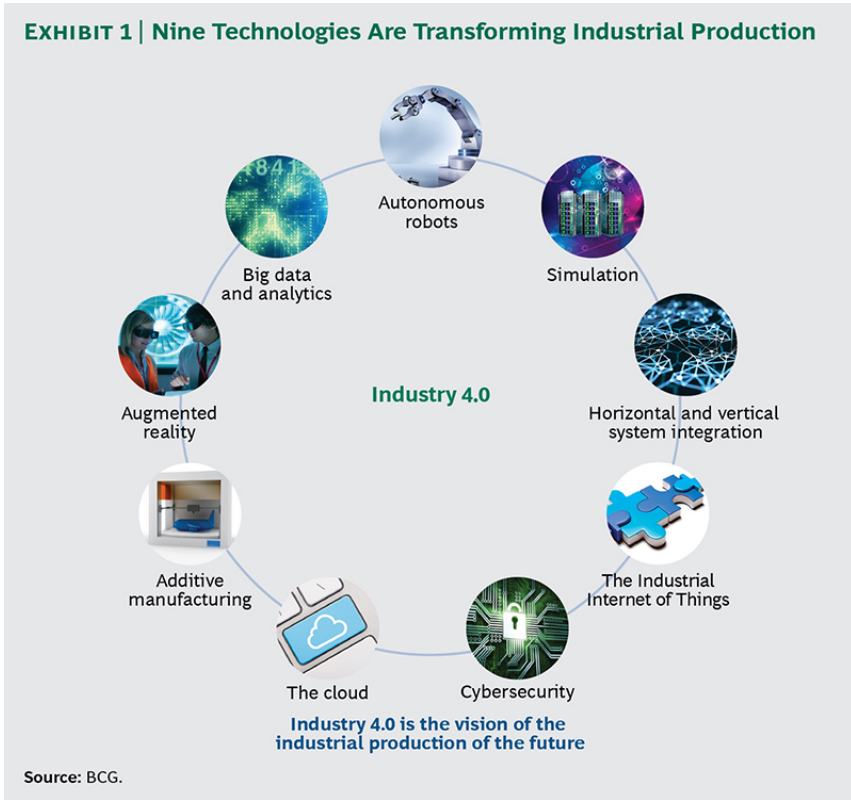

Figure 3: The nine main technologies (: BCG - Boston Consulting Group, ) [15]

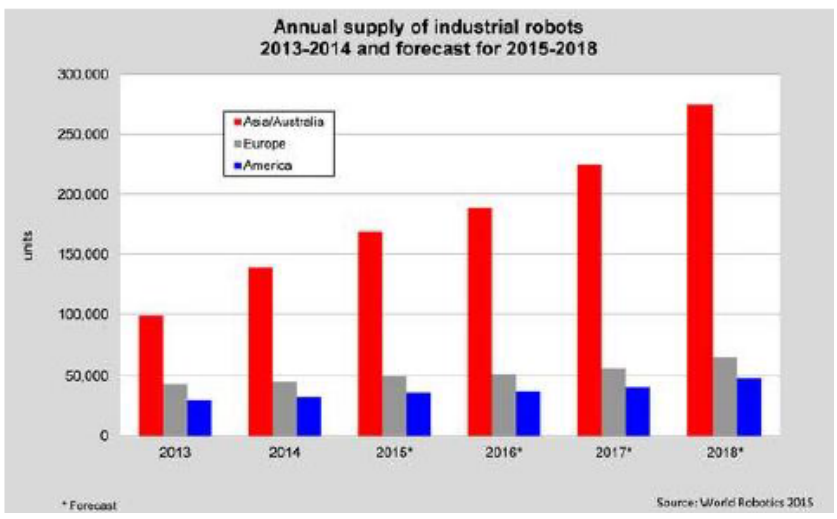

Figure 4: Industrial robots supply forecast (IFR) [12].

Robots improve the productivity favoring the savings on production and eliminating problems of lack of qualified manpower. Robots improve the quality of work by taking over dangerous, tedious and dirty jobs that are not possible or safe for humans to perform [12].

The high performance, low investment cost and most of all the adaptability of robots makes them the perfect choice for an efficient and easy automation solution. On this way, special software developed for robotics helps to improve the repeatability and the accuracy of robots' positioning. This feature contributes to meet the requirements of manufacturing aviation [13].

Due to be known as very conservative, the aerospace industry usually uses successful assembly methods that have already been proven to work in the past. But, in the past couple of years, the general attitude, in terms of assembly tasks, has really observed in the aerospace industry. Aircraft manufacturers tend to use robotics on some manufacturing applications to perform tasks that require precision and rigidity on big parts [14].
Investments with robots on aircraft manufacturing can be beneficial when the payback is feasible.

It follows few of the robotic applications in aerospace manufacturing (Figure 5) [29-31 and 33].

- Drilling

- Fastening

- Inspection

- $\quad$ Painting

- Fiber Placement

- $\quad$ Sealing

- Manipulation

On the Industry 4.0 way, another good application is collaborative robots. The main advantage of this kind of robot is the collaboration between human-robot in work together.

These intelligent robots begun automating new areas with their sensitive capabilities to detect workpiece positioning tolerances, work with non-rigid parts, open doors on machines, recognize component types and perform an infinite number of other tasks. The range of possible applications in the factory of the future is virtually infinite. These robots currently work in industry proves the collaboration between humans and robots works (as seen in Figure 6), even in the harsh environment of day-to-day production $[17,29,32,34,35]$.

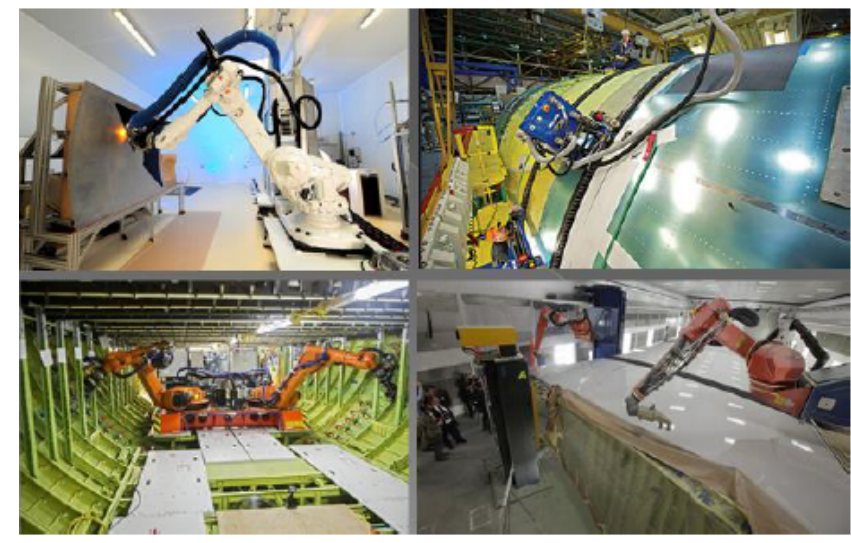

Figure 5: Robots application at aviation industry [29-31 and 33].

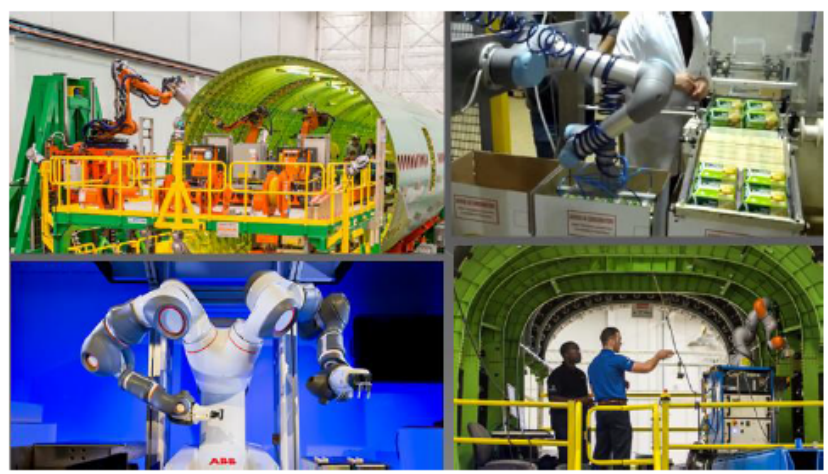

Figure 6: Collaborative robots applications [29,32,34 and 35]. 
Citation: Barbosa GF, Aroca RV (2017) Advances of Industry 4.0 Concepts on Aircraft Construction: An Overview of Trends. J Steel Struct Constr 3: 125. doi: 10.4172/2472-0437.1000125

Page 4 of 8

Where fences are no longer required between robots and humans, the way is paved for entirely new and highly productive approaches to industrial manufacturing. Its built-in sensor system allows the seamless integration and division of tasks between human and machine, with considerable advantages in terms of manufacturing efficiency and flexibility [17].

\section{Digital manufacturing}

Increasingly, simulations have been used in industrial operations, from the engineering phase, products' modelling and definitions of materials and production processes. Simulations compare on realtime data the physical world with a virtual model, which includes machines, products and people. This allows operators to test and optimize the machine settings for the next product on production in a virtual environment before changing to the physical condition, thus reducing the down time of machine setup and increasing the quality of the products [15].

It consists in a virtual integration on production shop floor, including equipment, products, planning, data and efficiency of operation. Digital manufacturing is also used to detect fails and interruptions of the production in order to reduce downtime, based on a virtual machine that can simulate the whole process (Figure 7) $[39,40]$.

Thus, digital manufacturing has been updated day-by-day at aviation industry due to key benefits [18] as follows:

- Factory simulation;
- Creates an assembly sequence that facilitates assembly preplanning;

- Provides assembly process modelling and sequence analysis;

- Enables users to perform assembly sequence analysis;

- Product assembly simulation in resource context;

- Provides for maintainability, supportability, and training;

- Enables step-by-step process documentation;

- Enables users to perform assembly sequence verification;

- Visualizes manufacturing and assembly procedures.

\section{Augmented Reality (AR)}

According to [28], Augmented Reality (AR) is defined as an integration of digital information with the user's environment in real time. It uses the real world and overlays virtual information on top of it to perform the augmentation.

Digital data can be input to visual or sound condition. When applied to visual, 3D digital objects are loaded and rendered within the physical world often using a display device like a tablet or smarthphone. Numerous advancements in AR have enhanced the feasibility of using AR in many applications [9].

The advantages and benefits of AR have been widely applied by important aircraft manufacturers in global market.
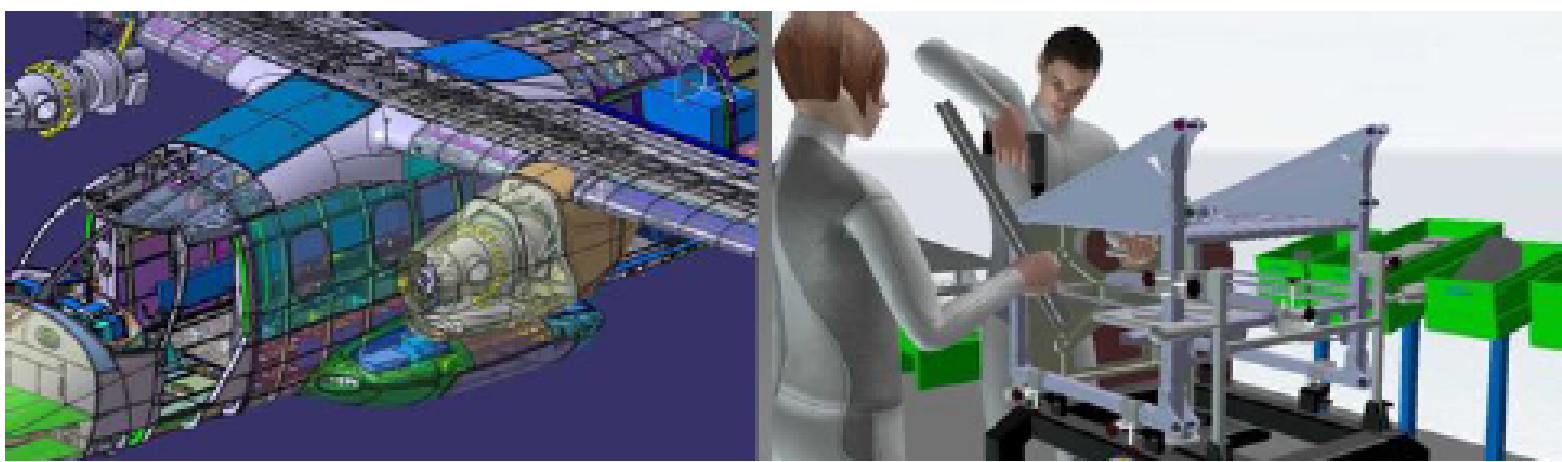

Figure 7: Digital manufacturing simulations (WN.com 2000 and cz.all.biz 2017) [39 and 40].

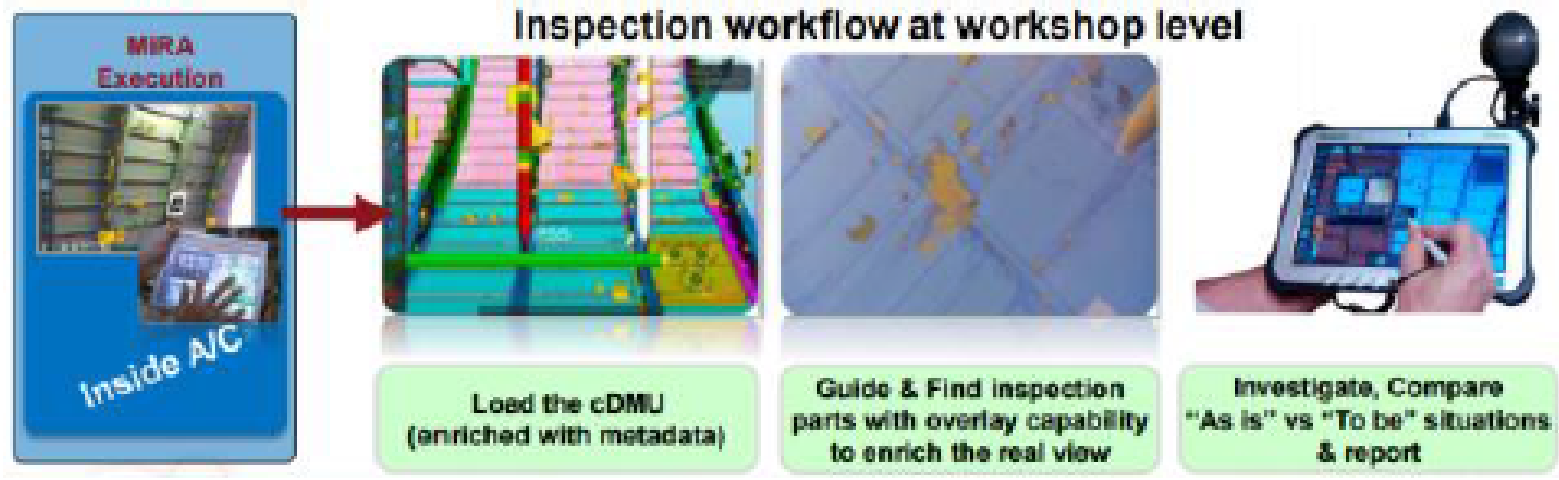

Figure 8: MiRA solution by TESTIA (Airbus Company) [10]. 
An important industrial application of AR is already used by Airbus. The solution of digital tools has been developed to assist the aircraft production process.

This AR solution was named MiRA (Mixed Reality Application) by Airbus. This application increases the productivity in production lines by using AR to scan parts and detect errors on structures.

For example, on A380 aircraft, MiRA contributes to a time reduction of $80 \%$ for inspection of brackets in the fuselage. Saving could be got due to integration of AR with a tablet and a special pack containing sensor and software. Also, other gains related to discoveries of damages, wrongly positioned or missing brackets have been reduced by $40 \%$ [10] (Figure 8 ).

A specific application of AR technology has been used on Airbus factories. On the shop floor, tablets and sensors are installed inside the aircraft fuselage in order to track the position of parts and relate them to full-scale CAD models of the real. So, this allows downloading an image of the part in the area where they are working to ensure that they have fixed it correctly. Location tags attached inside the fuselage interact with the sensors to allow the visualization of the tasks from any work location.

Another saving is the reduction of the time to inspect brackets inside an A380 fuselage, which hold systems such as hydraulics pipes [11].

\section{Additive manufacturing (AM)}

Additive Manufacturing (AM), also called 3D printing process, provides a new and interesting approach to industrial production.

Opposed to conventional manufacturing processes that obtain a part from a solid blank of raw material, the AM works from the inside out, constructing the end part layer by layer. Repeatedly, the AM process prints very thin layers of material over the other until the layers form a solid component, that can be printed by different materials like plastics, aluminium, titanium, glass and concrete with high quality [10].

Figure 9 represents the steps of AM process used for any part fabrication.

The AM process does not require manufacturing tools, which distinguishes the $3 \mathrm{D}$ printing from conventional subtractive manufacturing methods. This allows the construction of complex shapes parts and assists in reducing manufacturing time and costs, and simplifies inventory management. Companies started to use AM process of $3 \mathrm{D}$ printing using them for prototyping and production of individual components [43].

Inside the context of Industry 4.0, AM process will be widely used to manufacture customized products in all sectors of industry. Some benefits like manufacturing of complexes shape parts, getting of lightweight parts and reduction of tooling can be provided by AM. Also, reduction of transportation distances and stock on hand are other advantages [15].

For example, aircraft industry always looks to apply new designs that reduce aircraft weight, lowering their expenses with raw materials such as titanium. On this way, manufacturers have been already using $\mathrm{AM}$ on their processes [15].

With the use of 3D printed parts across the aircraft platforms, there is a huge opportunity on this process application, even if $3 \mathrm{D}$ printing

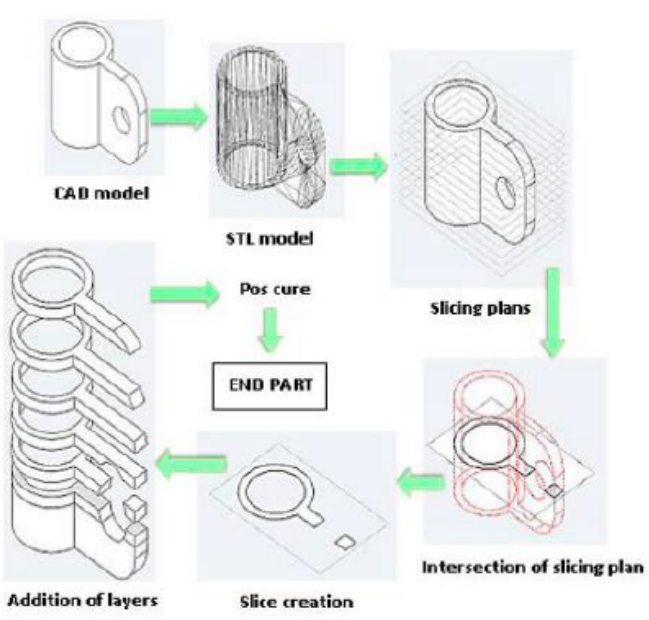

Figure 9: Additive Manufacturing process (Bessa) [19].

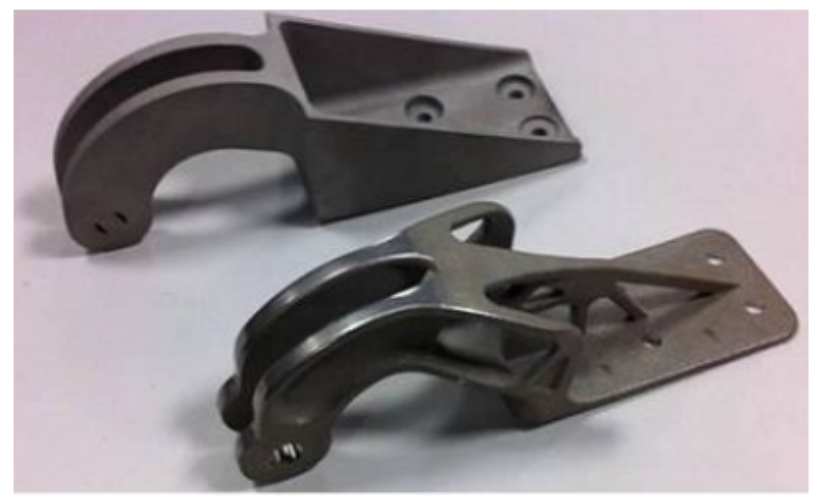

Figure 10: Additive manufacturing process (3Ders) [22].

only represents $1 \%$ of total parts in a commercial aircraft, for example [20].

The $3 \mathrm{D}$ printing process makes the production of very complex shapes easier. An electron or laser beam is used to model the desired metallic material according to a CAD (Computer Aided Design) generated by the computer. Thus, parts designed for and manufactured by AM can have a natural and trustful shape, which would be impossible if producing them from a solid block of material, beyond the wastes of material. Such parts are lighter, faster to produce and ultimately much less expensive than conventional ones [21 and 22].

For example, the Boeing company clearly understands how the technology offers the potential to change the aviation industry for the better. So, 3D printing gives the ability to improve how spare parts are made by reducing lead times and costs, which also contributes to a shorter maintenance times and less consumption of raw material, improving the competitiveness [20].

\section{RFID}

The name "Radio Frequency IDentification" implies the transponders and reading devices in RFID systems communicate with one another via radio as showed in Figure 11. The RFID systems use a variety of carrier frequencies, depending on the application [23 and 36]. 
Intelligent RFID (Radio Frequency Identification) tags could soon function as minicomputers that guide products on their paths through factories, stores or countries. RFID tags could be attached to many different things. Jeans, pharmaceutical products, and even cars, for example, are equipped with a tag so they can be identified beyond doubt during shipping. The principle is simple: if an object with an RFID tag, otherwise known as a transponder, passes a matching reader, the tag is activated and reveals the information stored in its memory. A manufacturer can thus know exactly when a product left its factory, a middleman can track it as it continues on its course and when the product arrives at its destination, the organization that processes it can confirm its status as "received" [23].

In Industry 4.0 context, new applications for these tags in the field are being developed to assist collaboration between computational elements and physical entities.

With the RFID technology, aircraft manufacturers are able to use this trend on their processes. For example, workstations and eventually work pieces themselves could be equipped with RFID tags holding all the data relevant to production of an item as the item itself are carried through a plant. RFID scanners read the data and issue corresponding commands to robots and its systems. An interesting application is to control of the tools in the manufacturing environment that is not an easy task due to recurring loans and drives of them during the work shifts. Coupled to this, same tools are shared or specific use and may be

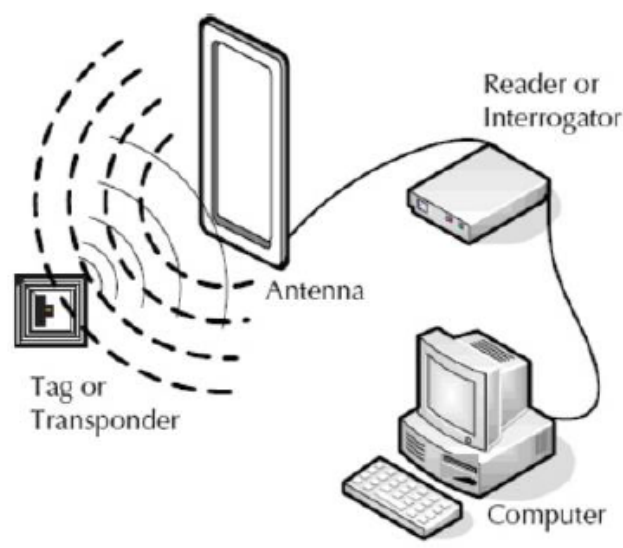

Figure 11: RFID concept (Agarwal 2015) [36].

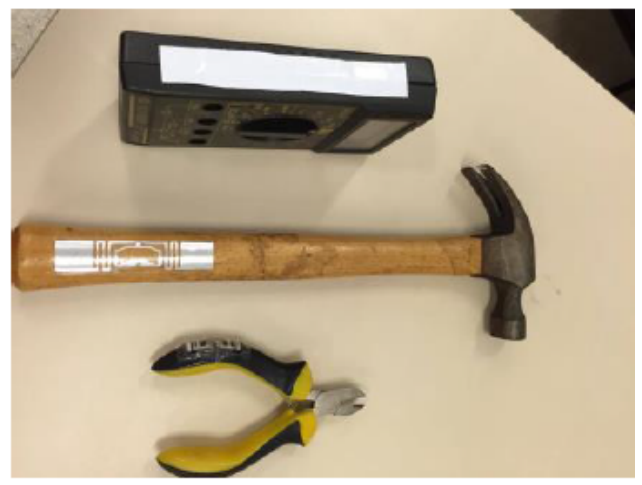

Figure 12: Tools with RFID tags (Barbosa, et al 2016) [41]

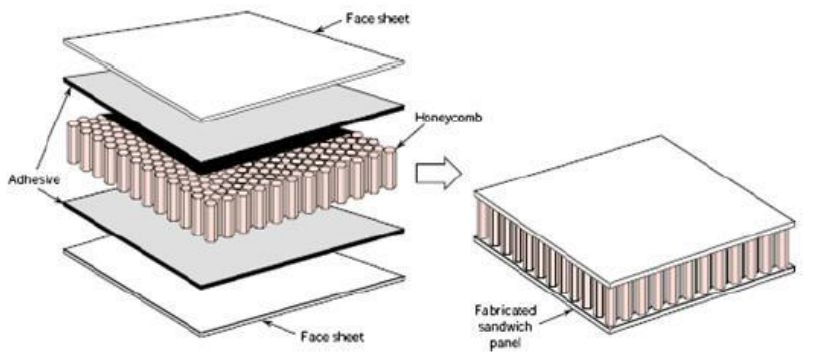

Figure 13: Composite material composition (admatis.com 2015) [37].

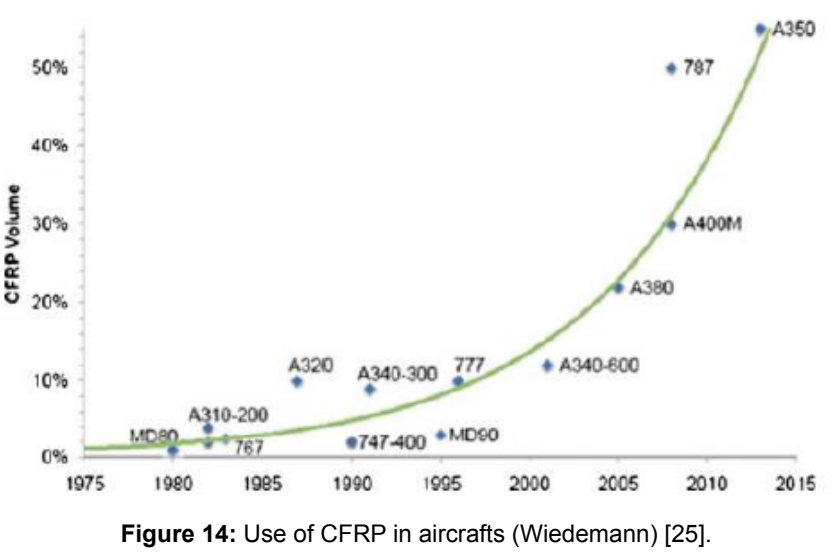

of different sizes, with likely potential chances to be lost or forgotten in unwanted places. Based on that, an application has been developed to be used on aircraft shop floor for providing management of those [41]. Figure 12 shows an example of it.

A management system allows to view the status of each tool, and thereby, monitor the usage time per user and application, allowing optimize the allocation of use of more expensive tools and less availability. It can save money when a production ratio increases and demands of tools up.

\section{Composite materials}

Composites can be defined as advanced construction materials composed by fiber + resin as illustrated in (Figure 13) [37].

According to [24] the spread of composites material components made of CFRP (Carbon Fiber Reinforced Plastic used in aircraft has increased exponentially over the last years. Figure 14 shows the trend of using CFRP in modern aircraft [25].

It follows the main advantages of using composite materials on aircrafts design and manufacturing:

- $\quad$ Saving of manpower labour

- High specific strength and stiffness

- Increased service life

- No corrosion

- Greater resistance to fatigue,

- $\quad$ Reducing the number of parts, 


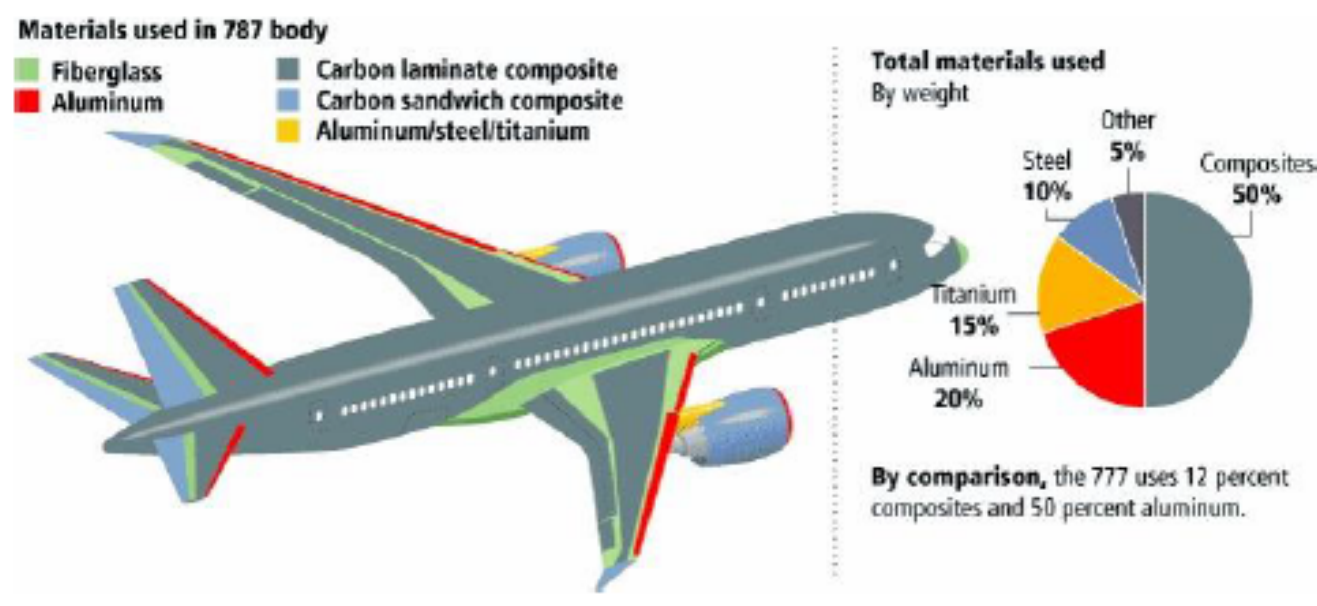

Figure 15: Materials used in 787 aircraft (modernairliners.com) [26]

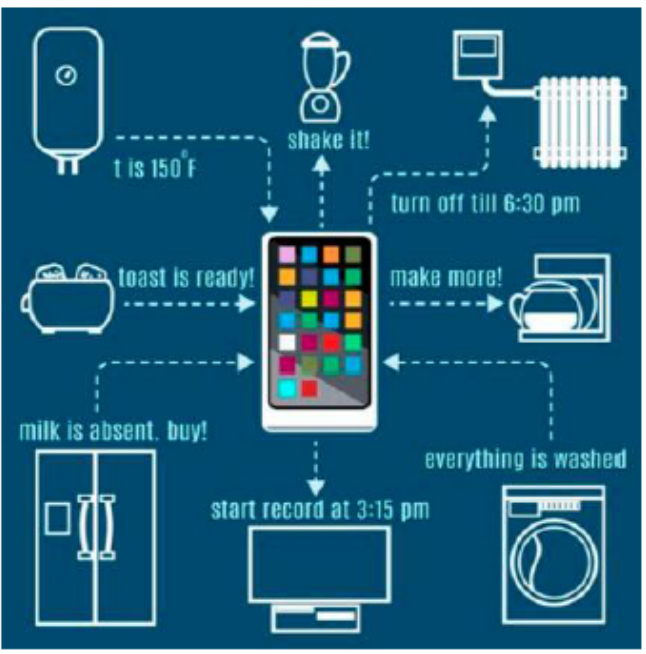

Figure 16: loT concept Rosenbaum (2015) [38]

- Obtaining of complex geometries,

- $\quad$ Lower weight

Aircraft manufacturers are increasingly adopting composite materials to reduce aircraft weight and operating costs. Composite airframe manufacturing involves the fabrication of large single-piece parts, an expensive process [24].

The fuselage of the Airbus A350 XWB, for example, is made up of a number of large composite panels which are then joined together (Figure 15) [26].

This increase in composite usage has also brought a series of advantages as: fuel efficiency, passenger comfort and environmental impact, which will keep growing in the future.

\section{IoT - Internet of Things}

The IoT concept can be defined as the use of internet technologies. It covers the wireless connection, micro-electromechanical systems, software and Apps. This approach has helped the linkage between Operational Technology (OT) and Information Technology (IT), allowing unstructured machine-generated data to be analysed for monitoring that will orient improvements on production systems [27].

Every "thing" will soon be networked. Even today, almost every electronic device is able to communicate with the Internet. Digitization is triggering rapid developments in any area and digitally networked processes in Industry 4.0 will make it possible to manufacture products at a low cost in a manner that is more flexible, energy-efficient, resource-saving and customized [17].

Thus, aviation manufacturing has looked for solution in order to integrate robots, systems and devices by tablets and smartphones via Apps (Figure 16).

\section{Conclusion}

This paper has reviewed the most important Industry 4.0 technologies applied on aircraft manufacturing industry toward to the future, moreover the composite materials trend on this sector.

Everyday physical devices have been connected to the Internet and be able to identify themselves to other devices (robots, machines and equipments).

Smart sensors with embedded intelligence, that can communicate for control and integrate with enterprise business systems, represent a clear system architecture change for process automation and control. Also, it is a revolutionary change and challenge for the industry, when compared to its traditional production system.

The potential worldwide impact of Industry 4.0 has provided technological advancements and benefits in four areas:

- $\quad$ Productivity

- $\quad$ Revenue Growth

- Employment

- Investment

Future production system demands for manufacturing agility to efficiently respond to changes in demand, technologies and product variations.

By the way, the aviation manufacturing industry has faced to the globalized aerospace market that requires aircraft manufacturers to 
Citation: Barbosa GF, Aroca RV (2017) Advances of Industry 4.0 Concepts on Aircraft Construction: An Overview of Trends. J Steel Struct Constr 3: 125 . doi: $10.4172 / 2472-0437.1000125$

Page 8 of 8

remain current and push the boundaries of aircraft manufacturing processes to the competitiveness.

On this way, it can be concluded that the Industry 4.0 principles can contributes significantly to assist new manufacturing processes on aviation industry and a raise in collaboration productivity.

Besides that, it introduces an approach of Industry 4.0 at aircraft production in order to support the increase efficiency of production systems at such factories. By collecting data from shop floor (processes, machines, etc.) and by providing them to decision makers in real time at any place (by mobile devices), the factory can be improved in reducing of wastes.

In addition, this approach aims to promote the spread of Industry 4.0 concepts in aviation manufacturing and its advantages that can be achieved.

Finally, Industry 4.0 provides other gains such as: productivity, standardization, ergonomics, cleaning, maintenance, workmanship and innovation that were not accounted in this study, based on IoT and Smart Production that connects the digital and real worlds.

\section{References}

1. Wagels C, Schmitt R (2012) Benchmarking of Methods and Instruments for Self-Optimization in Future Production Systems. In 45th CIRP Conference on Manufacturing Systems, pp: 161-166.

2. Barbosa GF, Carvalho J, Filho EVG (2014) A proper framework for design of aircraft production system based on lean manufacturing principles focusing to automated processes. The International Journal of Advanced Manufacturing Technology 72: 1257-1273.

3. Hermann M, Pentek T, Otto B (2015) Design Principles for Industrie 4.0 Scenarios: A Literature Review. Technische Universität Dortmund Fakultät Maschinenbau.

4. Seitz F, Steele LW (1985) The Competitive Status of the U.S. Civil Aviation Manufacturing Industry. National Academy Press, Washington DC.

5. Barbosa GF (2012) Desenvolvimento de um modelo de análise para implantação de automação na manufatura aeronáutica, orientado pelos requisitos das metodologias de Projeto para Excelência (DFX - Design for Excellence) e Produção Enxuta (Lean Manufacturing). Ph.D. dissertation, Dept. Mechanical Eng., Escola de Engenharia de São Carlos da Universidade de São Paulo (USP)

6. Composites Forecasts and Consulting LLC.

7. Lasi H, Fettke P, Kemper HG, Feld T, Hoffmann M (2014) Industry 4.0. Business \& Information Systems Engineering. 6: 239-242.

8. Lins T (2015) Indústria 4.0 Desafios Parte 1. iMobilis. Laboratório Imobilis Computação Móvel.

9. Richardson T, Gilbert S, Holub J, Thompson F, MacAllister A, et al. (2014) Fusing self-reported and sensor data from mixed-reality training. In Proc. Interservice/Industry Training, Simulation, and Education Conference, pp: 1-12.

10. Airbus Company.

11. The Engineer (2015) In touch with reality: the digital future of the factory. Available on, May.

12. IFR (2015) Industrial Robot Statistics. International Federal Robotics World Robotics.

13. Broetje Automation (2014) Integrated Section Assembly Cell. Available on.

14. Barrette B (2014) M Top 5 Robotic Applications in the Aerospace Industry. Robotiq.

15. BCG - Boston Consulting Group (2016) The Nine Pillars of Technological Advancement. Industry 4.0: The Future of Productivity and Growth in Manufacturing Industries.

16. Staff, ATP Electronics (2015) Automation Industry Industry 4.0 Challenges and Solutions for Storage Devices.
17. Kuka AG (2016) Hello Industrie 4.0_we go digital. KUKA Aktiengesellschaft Zugspitzstraße 140, 86165 Augsburg, Germany, 2016.

18. Dassault Systèmes (2016) DELMIA DPM Assembly Process Simulation 2 (APS), Delmia.

19. Silva RJ, Barbosa GF, Carvalho J (2015) Additive Manufacturing of Metal Parts by Welding. IFAC-PapersOnLine, 48: 2318-2322..

20. Global Manufacturing (2015) Boeing reduces lead time and saves money by $3 d$ printing aircraft parts. Accessed on.

21. Airbus Group (2017) 3D printing Building from the inside. Factory of the future. New ways of manufacturing factory of the future.

22. 3Ders (2015) Northwestern University study confirms 3D printed metal parts help reduce aircraft weight by $7 \%$. 3D printer and 3D printing news.

23. Siemens (2015) RFID-Tags: Rewriting the Rules of Logistics. Pictures of the Future - The Magazine for Research and Innovation.

24. Ehinger C, Hoffmann A, Reif W, Reinhart G, Strasser G (2010) Automated cutting and handling of carbon fiber fabrics in aerospace industries. $6^{\text {th }}$ IEEE International Conference on Automation Scienceand Engineering, CASE 2010, Toronto, pp: 861-866.

25. Wiedemann M (2009) CFRP status of application in airframe structures and future development process. NAFEMS World Congress, Crete, Greece.

26. Modern Airliners. Boeing 787 Specs, Dreamliner Materials Pictorial.

27. Rouse M (2016) Internet of Things (IoT). IoT agenda. Techtarget.

28. Margaret R (2016) Augmented Reality (AR) Whatsls.com.

29. Waurzyniak P (2015) Aerospace Automation Stretches Beyond Drilling and Filling. SME Manufacturing Engineering.

30. Weber A (2015) Assembly Automation Takes Off in Aerospace Industry. Assembly magazine.

31. Gates D (2013) Painting robots speed production of Boeing 777s. USA today.

32. Gates D (2016) Boeing South Carolina no longer playing catch-up to local plants. The Seattle Times.

33. RadioBreizh.bzh (2015) Succès Pour Les Un An Du Plateau Technique Compositic.

34. ABB (2014) ABB unveils the future of human-robot collaboration YuMi®.

35. Universal Robots (2015) Universal Robots quadruples injection molding output at Dynamic Group.

36. Agarwal T (2015) RFID - A Basic Introduction \& Simple Application. EL-PROCUS.

37. Advance Materials in Space (2015) Sandwich structures.

38. Rosenbaum R (2015) How Internet of Things affects your corporate network BITSIGHT Technologies.

39. WN.com (2005) DELMIA Delivers Version 5 Release 5, Enhanced Solutions Supporting Digital Manufacturing

40. Development of aircraft and aviation equipment.

41. Barbosa GF (2016) Uso da tecnologia RFID (Radio Frequency Identification) para gestão de ferramentas no ambiente da manufatura. CONEM - Congresso Nacional de Engenharia Mecânica. 